\title{
Avoidance and retention deficits in septal cats'
}

\author{
Robert A. MeCleary and Caroline Jones, UNIVERSITY OF CHICAGO \\ Holger Ursin, ${ }^{2}$ UNIVERSITY OF OSLO
}

\begin{abstract}
Thirteen cats with bilateral septal lesions were tested on a passive-avoidance task and also tested for retention of a preoperatively learned active-avoidance habit. Deficits in passive-avoidance behavior and losses in retention were produced by septal damage. There was no consistent relationship between the occurrence of the two abnormalities in the operated Ss.
\end{abstract}

\section{Problem}

Septal lesions produce a deficit in passive-avoidance behavior but do not interfere with the acquisition of an active-avoidance habit (King, 1958; McCleary, 1961). These findings and subsequent ones have been interpreted to mean that, under certain circumstances, septal Ss are deficient in the ability to suppress learned responses (McCleary, 1961; Kaada et al., 1962; Lubar, 1964; Fox et al.,1964; Schwartzbaum et al., 1964; Zucker \& McCleary, 1964). Moore's (1964) recent report that septal lesions also disrupt the retention of a preoperatively learned a ctive-avoidance response, however, is not explainable in terms of a deficiency in response suppression. The present study thus attempted to see whether or not a loss in retention of an activeavoidance habit and a deficiency in passive-avoidance behavior are associated effects of localized septal lesions.

\section{Method}

All Ss were first trained, 10 trials each day, to a 9 out of 10 criterion for five consecutive days on a 'one-way' active-avoidance problem. The apparatus already has been described in detail (Lubar, 1964). Basically, it consisted of two identical boxes whose relative positions could be reversed between successive trials. The CS was a 10-sec. buzzer and the US was an intermittent floor-shock supplied by a $1082 \mathrm{v}(\mathrm{ac})$ source with 500,000 ohms internal impedance. To avoid the shock, S could jump from the posteriorly positioned box into the anterior one. The positions of the boxes then were reversed prior to the next trial.

After the experimental Ss were lesioned, they first were given a passive-avoidance test and then checked for retention of the preoperatively learned activeavoidance habit. The passive-avoidance test has been described previously (McCleary, 1961). Briefly, Ss are shocked at an accustomed feeding place and then allowed fifteen trials in which they can passively avoid the threat of further shock by failing to approach the food, as do most normal Ss, or can demonstrate a deficit in passive avoidance by returning to the potentially punishing source of reward during the test trials. Retention of the preoperatively learned active-avoidance habit was measured by presenting ten $15-\mathrm{sec}$. test trials without shock reinforcement.

Ten Ss were lesioned electrolytically and five (Ss 6 , $8,9,12$, and 13) were lesioned by subpial suction. All lesions were verified histologically. Two Ss with electrolytic lesions (Ss 14 and 15) proved to have only unilateral septal damage and are included in the control group.

\section{Results}

As shown in Table 1, the control Ss passively avoided the offered food on all fifteen post-shock trials and showed perfect, or nearly perfect, retention of the preoperatively learned active-avoidance habit during the ten postoperative test trials. The septal Ss are ranked in Table 1 according to decreasing severity of their passive-avoidance deficit. At the extremes, a score of zero means $S$ failed to passively avoid the food on any of the post-shock trials while a score of 15 represents completely normal passive-avoidance behavior.

It is apparent that the retention data in Table 1 follow no systematic pattern in relation to the passiveavoidance performance of the septal Ss. There are perfect retention scores at both the top and bottom of

Table 1. Passive-Avoidance and CAR Retention Scores

$\begin{array}{ccc}\text { Subjects } & \begin{array}{c}\text { Passive-Avoidance } \\ \text { Score }\end{array} & \begin{array}{c}\text { Number of Correct } \\ \text { Responses during } \\ \text { Retention Test }\end{array} \\ 1 & 0 & 10 \\ 2 & 0 & 10 \\ 3 & 0 & 10 \\ 4 & 0 & 10 \\ 5 & 0 & 9 \\ 6 & 0 & 0 \\ 7 & 1 & 10 \\ 8 & 1 & 1 \\ 9 & 6 & 2 \\ 10 & 10 & 5 \\ 11 & 13 & 10 \\ 12 & 14 & 10 \\ 13 & 15 & 0\end{array}$

\section{Controls}

$\begin{array}{rrr}14 & 15 & 10 \\ 15 & 15 & 10 \\ 16 & 15 & 10 \\ 17 & 15 & 10 \\ 18 & 15 & 8\end{array}$


the passive-avoidance ranking and low retention scores are also scattered throughout the array of septal Ss.

Whether the lesion was made electrolytically or by subpial suction did not affect differentially the degree of passive-avoidance deficit; in the case of retention of the active-avoidance response, however, the four most deficient Ss all had been lesioned by subpial suction. No reason for this relationship can be suggested at the present time.

Histological analysis verified the presence of bilateral septal damage in all Ss of the septal group, but specific septal structures, whose damage was consistently correlated with either of the behavioral deficits, could not be identified. Damage to the medial septal nucleus and the descending columns of the fornix was most consistently related to the passive-avoidance deficit while lesions of the medial and lateral septal nuclei were observed in all Ss with a retention deficit. However, comparable damage was seen in still other Ss in whom the related behavioral abnormality was not present.

\section{Discussion}

The present findings confirm previous separate reports which have linked septal damage with deficits in passive-avoidance behavior and with losses in retention of a preoperatively learned active-avoidance habit. More importantly, the present results indicate that these two lesion-induced deficits can occur independently of one another. Thus, they presumably are dependent upon damage to two different functional systems within the septal area, although histological analysis supplied no information as to the structures involved in these two hypothetical systems. Because of the compactness and complexity of the septum, further attempts to differentiate the anatomical bases of these behavioral deficits might profit from lesioning various septal components where they extend beyond the septal area. Here, their greater physical separation would be more conducive to isolated surgical attack.

\section{References}

FOX, S. S., KIMBLF, D. P., \& LICKEY, M. E. Comparison of caudate nucleus and septal-area lesions on two types of avoidance behavior. J. comp. physiol. Psychol., 1964, 58, 380-386.

KAADA, B. R., RASSMUSSEN, E. W., \& KVEIN, O. Impaired acquisition of passive avoidance behavior by subcallosal, septal, hypothalamic, and insular lesions in rats. J. comp. physiol. Psychol., 1962, 55, 661-670.

KING, F. A. Effects of septal and amygdaloid lesions on emotional behavior and conditioned avoidance responses in the rat. J. nerv. ment. Dis., 1958, 126, 57-63.

LUBAR, J. F. Effect of medial cortical lesions on the avoidance behavior of the cat. J. comp. physiol. Psychol., 1964, 58, 38-46.

McCLEARY, R. A. Response specificity in the behavioral effects of limbic system lesions in the cat. J. comp. physiol. Psychol., 1961, 54, 605-613.

MOORE, R. Y. Effects of some rhinencephalic lesions on retention of conditioned avoidance behavior in cats. J. comp. physiol. Psychol., 1964, 57, 65-71.

SCHWARTZBAUM, J. S., KELLICUT, M. H., SPIETH, T. M., \& THOMPSON, J. B. Effects of septal lesions in rats on response inhibition associated with food-reinforced behavior. J. comp. physiol. Psychol., 1964, 58, 217-224.

ZUCKER, I., \& MCCLEARY, R. A. Perseveration in septal cats. Psychon. Sci.,1964, 1, 387-388.

\section{Notes}

1. This research was supported by NIMH Grant MH-5755 to Robert A. McCleary. The authors are grateful to Dr. R. Y. Moore for demonstrating his method of lesioning the septal area.

2. Research completed during tenure as USPHS International Postdoctoral Research Fellow (No. FF-272) at University of Chicago. 